\title{
A novel Rap1p-interacting factor, Rif2p, cooperates with Rif1p to regulate telomere length in Saccharomyces cerevisiae
}

\author{
David Wotton $^{1}$ and David Shore ${ }^{2,3}$ \\ Department of Microbiology, Columbia University College of Physicians and Surgeons, New York, New York 10032 USA; \\ ${ }^{2}$ Department of Molecular Biology, University of Geneva, CH-1211 Geneva 4, Switzerland
}

The Saccharomyces cerevisiae Rap1 protein binds with high affinity to sites within the poly $\left(\mathrm{C}_{1-3} A\right)$ tracts at telomeres, where it plays a role in both telomere length regulation and the initiation of telomeric silencing. Rap1p initiates silencing at telomeres by interacting through its carboxy-terminal domain with Sir $3 p$ and Sir4p, both of which are required for repression. This same domain of Rap1p also negatively regulates telomere elongation, through an unknown mechanism. We have identified a new Rap1-interacting factor (Rif2p) that plays a role in telomere length regulation. Rif2p has considerable functional similarities with a Rap1p-interacting factor (Rif1p) identified previously. Mutations in RIF1 or RIF2 (unlike mutations in the silencing genes $S I R 3$ and SIR4) result in moderate telomere elongation and improved telomeric silencing. However, deletion of both RIF1 and RIF2 in the same cell results in a dramatic increase in telomere length, similar to that seen with a carboxy-terminal truncation of Rap1p. In addition, overexpression of either RIF1 or RIF2 decreases telomere length, and co-overexpression of these proteins can reverse the telomere elongation effect of overexpression of the Rap1p carboxyl terminus. Finally, we show that Rif1p and Rif $2 p$ can interact with each other in vivo. These results suggest that telomere length regulation is mediated by a protein complex consisting of Rif1p and Rif2p, each of which has distinct regulatory functions. One role of Rap1p in telomere length regulation is to recruit these proteins to the telomeres.

[Key Words: Raplp; Rif1p; Rif2p; telomere length; transcriptional silencing; Saccharomyces cerevisiae]

Received November 4, 1996; revised version accepted January 31, 1997.

Telomeres, the ends of eukaryotic chromosomes, are specialized protein-DNA complexes typically based upon a simple DNA-repeat structure (TTAGGG in many multicellular organisms). Telomeres in the yeast Saccharomyces cerevisiae, which have an irregular repeat structure commonly abbreviated as $\mathrm{C}_{1-3} \mathrm{~A}$, are essential for chromosome stability (Sandell and Zakian 1993). The maintenance of telomeres in yeast (Singer and Gottschling 1994), and probably most other organisms, requires a unique reverse transcriptase, called telomerase, that can add telomeric repeats onto the chromosome ends (for review, see Blackburn 1994; Zakian 1995b). The length of telomeric repeats is variable between strains and individual clones of a given strain and can spontaneously increase or decrease (Shampay and Blackburn 1988), suggesting a balance between telomerase addition and degradation that is under complex genetic control

\footnotetext{
${ }^{1}$ Present address: Memorial-Sloan Kettering Cancer Center, Cell Biology and Genetics, New York, New York 10021 USA.

${ }^{3}$ Corresponding author.

E-MAIL David.Shore@molbio.unige.ch; FAX 41227026868.
}

(Lustig and Petes 1986; for review, see Greider 1996; Zakian 1995a).

The telomeric repeats in S. cerevisiae form high-affinity binding sites for the essential repressor/activator protein 1 (Raplp) (Shore and Nasmyth 1987; Buchman et al. 1988; Longtine et al. 1989) as often as once per $18 \mathrm{bp}$ (Gilson et al. 1993). Raplp plays two roles at telomeres, both of which are mediated by its carboxy-terminal domain (for review, see Shore 1995; Zakian 1995a): It is involved in transcriptional silencing, or telomere position effect (TPE) (Kyrion et al. 1993; Moretti et al. 1994), and it controls telomere length (Conrad et al. 1990; Lustig et al. 1990; Sussel and Shore 1991; Kyrion et al. 1992; Liu et al. 1994). Raplp is also involved in silencing at the HM mating-type loci (Kurtz and Shore 1991; Sussel and Shore 1991; Kyrion et al. 1993). The role of Raplp in transcriptional silencing appears to be the recruitment of specific repressor proteins (Sir3p and Sir4p) to the telomeres and $H M$ silencers via direct protein-protein interactions (Moretti et al. 1994; Cockell et al. 1995; Hecht et al. 1996). In addition to its specialized roles at telomeres and $H M$ silent mating-type loci, Raplp also binds to the 
upstream regions of many genes, including a large number of ribosomal protein and glycolytic enzyme genes, where the protein appears to function as a transcriptional activator (for review, see Shore 1994). Activation of transcription by Rap1p may be mediated by a region immediately amino-terminal to the silencing and telomere domain (Hardy et al. 1992a) and involves, at least in some cases, specific interactions with other DNA-binding activator proteins (Tornow et al. 1993; Drazinic et al. 1996).

Point mutations (e.g., $\operatorname{rap}^{\text {s }}$ ) and frameshift mutations (e.g., rap $1^{t}$ ) within the Raplp carboxyl terminus result in varying degrees of telomere tract elongation, suggesting that this domain regulates telomere elongation (Sussel and Shore 1991; Kyrion et al. 1992; Liu et al. 1994). However, this function of Raplp does not appear to be mediated directly by the Sir proteins. In fact, mutation of SIR3 or SIR4 actually results in slight telomere shortening (Palladino et al. 1993), suggesting that the normal function of these proteins in some way supports telomere elongation. Instead, a number of studies indicate that other proteins interact with the Raplp carboxyl terminus to negatively regulate telomere growth. For example, overexpression of the Raplp carboxyl terminus in the absence of its centrally located DNA-binding domain (Conrad et al. 1990; Hardy 1991) or introduction of extra telomere repeats into cells (Runge and Zakian 1989) results in telomere elongation, consistent with the idea that titratable Rapl-interacting factors control telomere length. One candidate for such a factor is Riflp, which was identified in a two-hybrid screen as a protein that interacts with the Raplp carboxyl terminus (Hardy et al. 1992b). Interestingly, the telomere elongation defect of rap $1^{s}$ mutants may result from an inability to bind Riflp: Mutant rap $1^{\mathrm{s}}$ proteins interact weakly or not at all with Riflp in two-hybrid assays, and disruption of RIF1 results in telomere elongation similar to that observed in severe rap $1^{s}$ mutants (Sussel and Shore 1991; Hardy et al. 1992b). However, several lines of evidence point to the existence of other Raplp-interacting factors involved in telomere length regulation. First, $\operatorname{rap} 1^{t}$ mutants (which completely lack the carboxyl terminus) have a much more severe telomere elongation phenotype than either rap $1^{s}$ or rif1 mutants (Kyrion et al. 1992). Second, point mutations in the Raplp carboxyl terminus with weak telomere elongation phenotypes display additive effects when present together or in combination with a RIF1 mutation (Liu et al. 1994; L. Sussel, S. Buck, and D. Shore, unpubl.). Finally, overexpression of the Rap1 carboxyl terminus causes further telomere elongation in RIF1 mutant cells, suggesting the existence of other Rap1p-interacting factors that regulate telomere length (Wiley and Zakian 1995).

Here we present the identification and characterization of a novel protein, which we call Rif2p (Rap1-interacting factor $2 \mathrm{p}$ ). This protein interacts with the carboxyl terminus of Raplp in the two-hybrid system, and is also able to interact with Riflp. Rif $2 p$ has striking functional similarities to Riflp, despite a lack of sequence similarity. However, deletion of both RIF genes has a strong synergistic effect on telomere length, resulting in telomere elongation similar to that seen in rap $1^{t}$ cells. We argue from these and other data that Riflp and Rif $2 p$ form a functional complex capable of regulating telomere length when recruited to telomeres by Raplp.

\section{Results}

\section{Isolation of RIF2}

To identify proteins that interact with Raplp and play a role in mediating Raplp-dependent functions, we have used the two-hybrid system to screen yeast genomic DNA libraries with a LexA/Rap1 fusion encoding amino acids 635-827 of Raplp. Previously we reported the isolation of clones containing SIR3 and SIR4, two genes directly involved in transcriptional silencing (Moretti et al. 1994). Here we describe the isolation and characterization of a new gene from this two-hybrid screen, which we call RIF2 (Rap1p-interacting factor 2). As shown in Table 1, the GAD/Rif $2 p$ hybrid encoded by the library plasmid interacts specifically with LexA/Rap1(635-827), but not with LexA alone or an unrelated LexA hybrid (LexA/lamin). Furthermore, when the reading frame between the GAD sequence and the RIF2 insert was disrupted (creating GAD/rif2fs) no activation of transcription was observed. Thus, the interaction with LexA/ Rap1(635-827) is dependent on the GAD/Rif2 fusion protein.

LexA/Rapl(635-827) contains not only the Raplp silencing domain, but also most of a transcriptional activation domain, which spans amino acids 630-695 (Hardy et al. 1992a). In addition, this hybrid protein has been shown to be a transcriptional activator in cells mutated for either SIR2, SIR3, SIR4, or RIF1 (Moretti et al. 1994). Therefore, we wanted to determine whether expression of the GAD/Rif2 fusion was able to cause increased activation from other LexA fusion proteins that are themselves weak or cryptic activators. Both LexA/Gcr1/4419) and LexA/Clb2(15-491) activate transcription from LexA operators to a low level. However, no increase in transcriptional activity of these fusions was observed in the presence of GAD/Rif2 (Table 2), further demonstrating that the interaction of GAD/Rif2 with Rap1p is specific. Sequence analysis of the GAD/Rif2 plasmid revealed that the insert encoded a large open reading frame

Table 1. GAD/Rif2 interacts specifically with LexA/Rap1

\begin{tabular}{lccc}
\hline & GAD & GAD/Rif2 & GAD/rif2fs \\
\hline LexA/Rap1 (635-827) & 7.1 & 249 & 6.9 \\
LexA & 3.5 & 3.7 & 3.6 \\
LexA/lamin & 3.7 & 3.7 & 3.4 \\
\hline
\end{tabular}

$\beta$-Galactosidase activity in CTY10-5D cells determined as described previously (Moretti et al. 1994).

${ }^{2} \mathrm{GAD} /$ rif2fs contains the same Rif 2 insert as GAD/Rif2 but has a frameshift mutation introduced between the GAL4 activation domain sequences and the RIF2 sequences. 
Table 2. GAD/Rif2 does not increase the function of other weak activators

\begin{tabular}{lrcc}
\hline & GAD & GAD/Rif2 & Fold increase \\
\hline LexA/Rap1 $^{\mathrm{a}}$ & 7.5 & 271 & 36.2 \\
LexA/Gcr1 $^{\mathrm{a}}$ & 39.3 & 29.2 & 0.7 \\
LexA/Clb2 $^{\mathrm{a}}$ & 44.6 & 33.3 & 0.8 \\
\hline
\end{tabular}

For determination of $\beta$-galactosidase activity, see Table 1 footnote.

${ }^{a}$ The LexA fusions used encoded amino acids 635-827 of Raplp, 4-419 of Gcr1p, and 15-491 of Clb2p.

(see below and Fig. 2A) fused in frame, at amino acid 14, with the GAL4 activation domain sequences.

\section{Localization of a minimal Rif2p-interacting domain within Rap1p}

Sir3p, Sir $4 p$, and Rif $1 p$ interact with a large portion of the carboxyl terminus of Raplp encompassing part of the putative activation domain and all of the sequences carboxy-terminal to it (Hardy et al. 1992b; Moretti et al. 1994). To determine whether a similar region was required for interaction with Rif $2 p$, we tested a series of LexA/Rapl fusions with increasing amino-terminal deletions. Proteins of the expected size for all LexA/Rap1 fusions were visible by Western blotting with a LexAspecific antiserum (data not shown). As shown in Figure 1, GAD/Rif2 was able to interact with amino-terminal truncations up to and including LexA/Rap1|679-827) (the numbers in parentheses indicate the Raplp amino acids present in the hybrid), but failed to interact with hybrids beginning at amino acid 691 or 702 in Raplp. This pattern is very similar to that of GAD/Sir3/307978) and GAD/Rif1(1614-1916), but unlike that of GAD/Sir4(1204-1358), which interacts only with the larger LexA/Rap1(635-827) hybrid (Moretti et al. 1994).

To determine the carboxy-terminal boundary of the Rif2p-interacting region of Raplp we used a series of LexA/Rapl fusions with a common amino-terminal fusion point, at amino acid 667. In contrast to the results obtained with Sir3p and Riflp hybrids (Moretti et al. 1994), in which mutation at amino acid 825 or deletion to amino acid 799 of Raplp severely weakened the interactions with these proteins, the same LexA/Rapl mutations actually increased the signal obtained with GAD/Rif2 (Fig. 1). The two shorter Raplp fusions tested, encoding amino acids 667-756 and 667-716, were unable to interact with GAD/Rif2. Thus, the region of Rap1p required for interaction with Rif2p lies between amino acids 679 and 799 . In contrast, the Raplp interaction with Rif1p or Sir3p requires amino acids 679-827, and an even larger region is required for interaction with Sir $4 \mathrm{p}$ (Moretti et al. 1994).

The results described above indicate that Rif2p can interact with a smaller region of the Raplp carboxyl terminus than that required by either Sir3p, Sir $4 p$, or Riflp, suggesting that the Rif2p-Rap1p interaction does not re- quire these other Rapl-interacting factors. To test this idea more directly, we examined the GAD/Rif2 interaction with LexA/Rap1(647-827) in strains containing mutations in either SIR3, SIR4, or RIF1. We chose this particular LexA/Rap1 hybrid because it still interacts with Sir3p and Riflp hybrids but does not become a transcriptional activator when SIR genes or RIF1 are mutated (Moretti et al. 1994). As shown in Table 3, mutation of SIR3 or SIR4 results in a $\sim 12$ - and 16 -fold increase, respectively, in the apparent interaction between Raplp and Rif $2 \mathrm{p}$. However, mutation of RIF1 results in a much more dramatic (>100-fold) increase in the Raplp-Rif2p interaction. These data clearly indicate that the RaplpRif $2 p$ interaction is not dependent upon native Sir3p, Sir $4 p$, or Rif $1 p$, and provide further support for the idea that this is a direct interaction. In addition, they raise the possibility that all three proteins (Sir3p, Sir4p, and Rif1p) compete with Rif2p for binding to the Raplp carboxyl terminus.

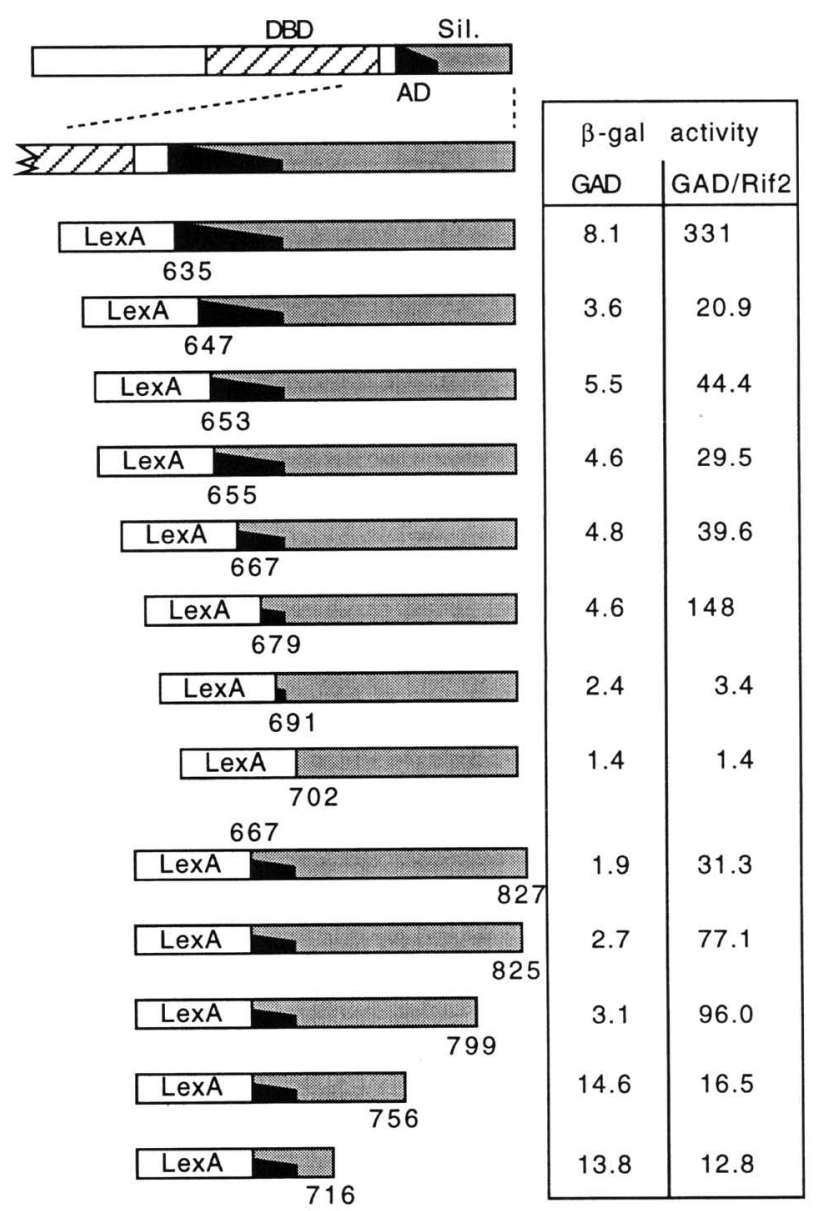

Figure 1. GAD/Rif2 interacts with amino acids 679-799 of Raplp. Two series of LexA/Rapl fusions with increasing amino- and carboxy-terminal truncations were assayed for interaction with GAD/Rif2 in CTY10-5D cells. $\beta$-Galactosidase activities were determined from liquid cultures as described previously (Moretti et al. 1994). Each fusion was also tested with GAD alone as a control. 
Table 3. Deletion of genes encoding known Rap1pinteracting factors increases the interaction of LexA/Rap1 with $G A D /$ Rif2

\begin{tabular}{lcc}
\hline & GAD & GAD/Rif2 \\
\hline Wild type & 3.6 & 20.9 \\
sir3::HIS3 & 5.7 & 259 \\
sir4::HIS3 & 5.9 & 332 \\
rif1::HIS3 & 4.9 & 2244 \\
\hline
\end{tabular}

For determination of $\beta$-galactosidase activity, see Table 1 footnote. In all cases, the DNA-binding domain hybrid is LexA/ Rap1 (647-827). The wild-type strain is CTY10-5D, and the mutants were derived from this strain by gene disruption (Moretti et al. 1994).

\section{Rif $2 p$ interacts with Rif1p}

An alternative explanation of the results described above (Table 3 ) is that Rif2p normally interacts with the Sir proteins or with Riflp (in addition to Raplp), and that the binding of GAD/Rif2 to these proteins somehow prevents or weakens a functional interaction with LexA/ Rapl in the two-hybrid system. In this case, mutation of the SIR or RIF1 genes might leave more GAD/Rif2 hybrid free to interact productively with LexA/Rapl. To explore this possibility we created a LexA/Rif2 fusion protein containing amino acids $2-395$ of Rif $2 p$. This fusion protein did not activate transcription on its own and no significant increase in $\beta$-galactosidase activity was observed upon coexpression of either GAD/Sir3 or GAD/Sir4, suggesting that these proteins do not interact with Rif2p (Table 4). However, a GAD/Rif1 fusion was able to interact with LexA/Rif2(2-395), giving a signal $>20$-fold over the background with GAD alone (Table 4). Thus, it appears that Raplp, Rif $1 p$, and Rif2p are all able to interact with each other. In light of these results, the simplest interpretation of the effect of SIR mutations on the Rif2p-Raplp interaction (Table 3) would be that Sir $3 p$ and Sir $4 p$ compete for binding to the Raplp carboxyl terminus with Rif2. In the case of Rif1p, because of the observed interaction with Rif $2 p$, we favor the idea that the RIF1 mutation improves the Raplp-Rif2 interaction by freeing GAD/Rif2 to interact more productively with the LexA/Rapl hybrid. However, we cannot rule out the possibility that Riflp also competes with Rif2 $\mathrm{p}$ for binding to Raplp.

\section{Rif $2 p$ and its interaction with Rif1p and Rap1p}

Analysis of the amino-acid sequence of Rif2p (Fig. 2A), reveals that it encodes a protein of 395 amino acids with a predicted molecular mass of $46 \mathrm{kD}$. (The RIF2 gene is on chromosome XII-R, hypothetical protein YLR453c, GenBank accession no. U22382.) Western analysis of epitope-tagged Rif2p, expressed from its own promoter, revealed a protein of the expected size (data not shown). This protein has no significant homology to other known sequences and no convincing structural motifs. The only notable features of the amino acid sequence of
Rif $2 \mathrm{p}$ are the presence of a lysine-rich region $(21.3 \% \mathrm{ly}$ sine) spanning amino acids $15-75$ and a second basic region at the carboxyl terminus $(17.1 \%$ lysine and $14.3 \%$ arginine over 35 amino acids).

To determine which region of Rif $2 p$ was responsible for the interaction with Raplp and Riflp, we created a series of LexA/Rif2 fusions and tested their interactions with GAD/Rap1 and GAD/Rif1. As shown in Figure 2B, truncation of the carboxyl terminus of Rif2p to amino acid 388 did not affect the interaction with Raplp or Riflp, but further truncation (to amino acid 332) abolished the interaction with both proteins. Both GAD/ Rapl and GAD/Rif1 were able to interact with Rif2p fusions starting at amino acid 2 or 18 . However, deletion of the first 49 amino acids of Rif $2 p$ abolished the interaction with Raplp (Fig. 2B). In contrast, the LexA/ Rif2(50-395) hybrid interacted strongly with GAD/Rif1, in fact giving more than twice as many $\beta$-galactosidase units as the LexA/Rif2(2-395) hybrid, which interacts with both Raplp and Riflp. A further deletion of 40 amino-terminal residues, giving LexA/Rif2(90-395), resulted in a hybrid unable to interact with either the Raplp or the Rif1p hybrid. Thus, Raplp and Riflp interact with largely overlapping regions of Rif $2 p$, although there does appear to be a difference between the regions of Rif $2 p$ required for interaction with these two proteins. The fact that GAD/Rif1 interacts with LexA/Rif2/503951, whereas GAD/Rapl is unable to, suggests that the Rif1p-Rif2p interaction is independent of Rap1p.

We further analyzed these interactions using cells in which either RIF1 or RIF2 had been deleted. A RIF2 disruption was created by replacing the sequence encoding amino acids $18-389$ of Rif2p with the HIS3 gene. Cells lacking the RIF2 gene were viable and appeared to grow normally. Deletion of either RIF1 or RIF2 did not result in loss of any of the interactions described above between Raplp, Riflp, and Rif $2 p$, suggesting that none of these proteins is bridging the interactions between any other pair (data not shown).

\section{RIF2 mutation affects silencing at both HMR and telomeres}

The known Raplp-interacting proteins, Sir3p and Sir4p on the one hand, and Riflp on the other, clearly play different roles in transcriptional silencing. Null mutations of either SIR3 or SIR4 completely abolish silencing at both telomeres and $H M$ loci (Ivy et al. 1986; Rine and

Table 4. Rif $2 p$ interacts with Rif $1 p$

\begin{tabular}{lcccc}
\hline & GAD & GAD/Sir3 & Gad/Sir4 & GAD/Rif1 \\
\hline LexA & 5.1 & 4.8 & 5.3 & 6.0 \\
LexA/Rif2 & 4.5 & 9.1 & 7.1 & 91.7 \\
\hline
\end{tabular}

For determination of $\beta$-galactosidase activity, see Table 1 footnote. The GAD fusions are as described in Moretti et al. (1994). The LexA/Rif2 fusion encodes amino acids 2-395 of Rif2p and was generated by PCR (see Materials and Methods). 
Figure 2. Rif2 $p$ residues required for the interactions with Raplp and Riflp. $(A)$ The predicted amino-acid sequence of Rif2p. The position of the original GAD fusion isolated is indicated by an arrow. A lysine-rich region near the amino terminus and a basic carboxy-terminal stretch are underlined. (B) A series of LexA/Rif2 fusions were created to identify the region of the protein required for interaction with Raplp and Riflp. $\beta$-Galactosidase activities were determined as in Fig. 1.
A

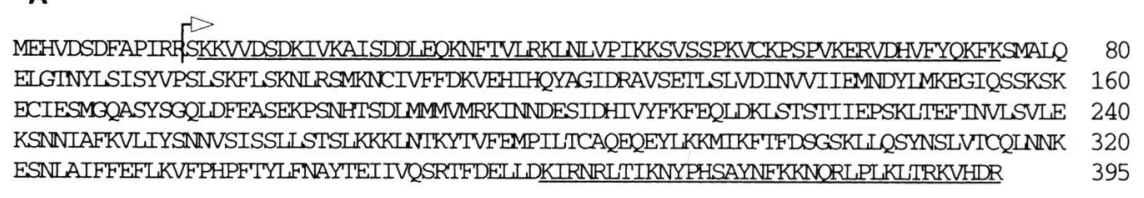

B

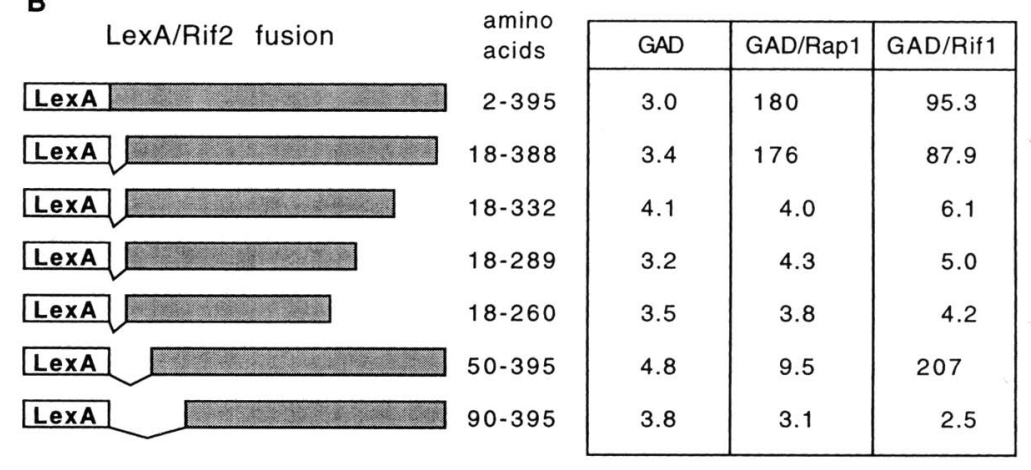

Herskowitz 1987; Aparicio et al. 1991). RIF1 mutations, however, actually improve silencing at telomeres while weakening repression at $H M R$ loci containing a mutated $H M R$-E silencer (Hardy et al. 1992b; Kyrion et al. 1993). It is thought, therefore, that $\operatorname{Sir} 3 \mathrm{p}$ and Sir4p are absolutely required for silencing, consistent with the observation that these proteins appear to be structural components of silent chromatin (Hecht et al. 1995, 1996). Rif $1 \mathrm{p}$ appears to play a regulatory role in silencing by affecting the balance between telomeric and HM locus silencing, a conclusion that is supported by studies of the unusual properties of $\operatorname{rap} 1^{s}$ mutations, which create a defect in the Raplp-Riflp interaction (Buck and Shore 1995).

We therefore examined the effect of RIF2 mutation on silencing at $H M R$ and at a genetically marked telomere. To examine silencing at $H M R$, we used a sensitive reporter gene (TRP1) and an HMR-E silencer containing a mutation of the origin recognition complex (ORC) binding site (HMR $\triangle A:: T R P 1)$ (Sussel and Shore 1991). rap1 ${ }^{s}$ and rif1 mutations result in derepression at $H M R$ only in the context of this weakened silencer (Sussel and Shore 1991; Hardy et al. 1992b). In an otherwise wild-type strain background, the $h m r \triangle A:: T R P 1$ reporter is strongly repressed, as indicated by the absence of growth on medium lacking tryptophan (SC-Trp, Fig. 3A). Little or no effect of a RIF2 mutation alone is observed, whereas deletion of RIF1 results in a clear increase in the expression of the TRP1 reporter gene at $H M R \Delta A$, as reported previously (Hardy et al. 1992b). Interestingly, despite the absence of a clear effect of the rif2 mutation, introduction of the rif2 disruption into a rif1 HMR $\triangle A: \because T R P 1$ strain led to a significant further derepression of the reporter gene, as indicated by the ability of essentially all of the cells to grow in the absence of tryptophan (Fig. 3A). Thus, although a rif2 mutation alone has little or no effect on $H M R$, in combination with a rif1 mutation it has a synergistic effect on silencing at this locus.

To examine the effects of RIF mutants on telomere
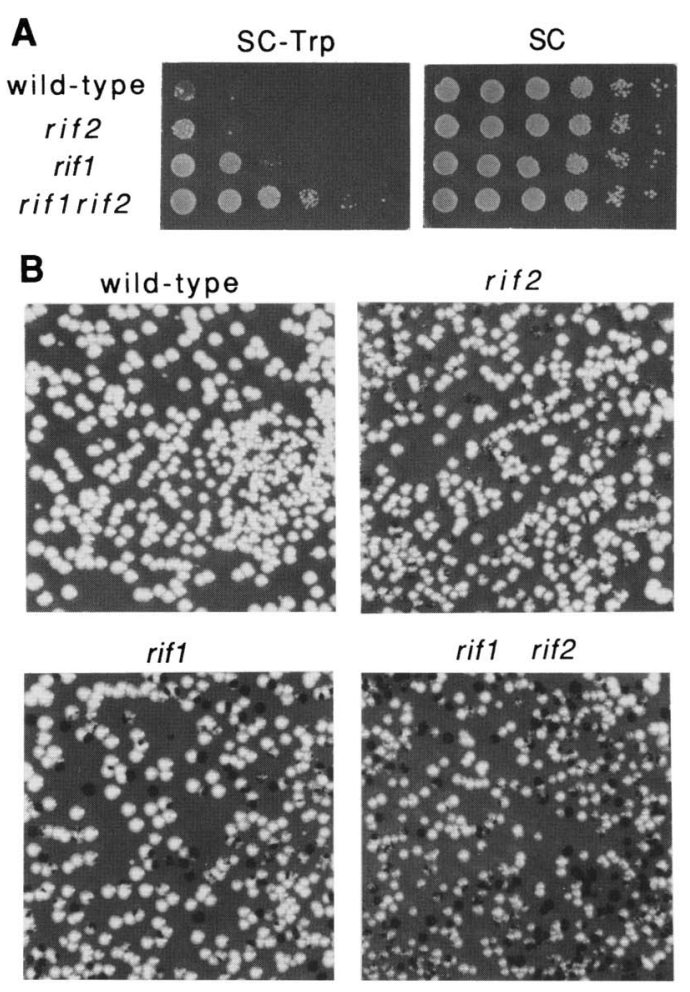

Figure 3. Deletion of RIF2 affects silencing. $\{A\}$ Strains were created with an $h m r \triangle A:: T R P 1$ reporter and gene disruptions of either RIF1, RIF2, or both together. YDW76 (RIF1 RIF2), YDW123 (rif1::URA3 RIF2), YDW77 (RIF1 rif2::HIS3), and YDW124 (rif1::URA3 rif2::HIS3) were assayed for TRP1 expression (see Materials and Methods). The relevant genotypes are shown on the left. (B) Telomeric silencing in strains (YDW84, YDW85, YDW86, and YDW87) with a telomeric $A D E 2$ reporter was assayed by colony color. Repression of the telomeric $A D E 2$ gene results in red sectors or colonies and $A D E 2$ expression results in white colonies. A single white colony of each strain was grown overnight in YPD and 200-300 cells were plated onto YPD plates. Cells were photographed after $2-3$ days at $30^{\circ} \mathrm{C}$ and 2 days at $4^{\circ} \mathrm{C}$. 
position effect (TPE), we assayed the expression of a telomeric $A D E 2$ reporter gene by observing colony color. Expression of $A D E 2$ results in white colonies, whereas in cells that do not express the $A D E 2$ gene red colonies are observed on plates containing minimal adenine. Colonies containing red and white sectors represent a mixed population of cells in which the $A D E 2$ gene is repressed as well as expressed. For each strain, a single white colony was picked and grown overnight in rich medium, after which 200-300 cells were spread onto YPD plates and the colony color observed. In wild-type cells very few sectored or red colonies were observed $(<1 \%)$, suggesting that the $A D E 2$ gene was expressed in most cells, and that this derepressed state was relatively stable (Fig. $3 \mathrm{~B})$. Deletion of RIF2 resulted in a small but reproducible increase in the number of sectored colonies to $\sim 11 \%$ (Fig. $3 \mathrm{~B}$. Mutation of RIF1 has been shown previously to increase TPE (Kyrion et al. 1993), and as shown in Figure $3 \mathrm{~B}$, this effect is larger than that seen in rif2 mutants ( $-34 \%$ sectored colonies). In cells lacking both Riflp and Rif2 $p$, a large proportion of the colonies was either completely red or contained red sectors $(>50 \%$; Fig. $3 \mathrm{~B})$. Thus, although mutation of RIF2 increased telomeric silencing only slightly, it had a synergistic effect when combined with a rif1 mutation.

In summary, the rif1 phenotype is stronger than that of rif2 in both $H M R$ silencing and TPE assays. Furthermore, despite the relatively weak effect of a rif2 mutation in either assay, it has a strong synergistic effect together with a rif1 mutation on the balance between telomeric and $H M R$ silencing, significantly strengthening the former and weakening the latter.

\section{RIF1 and RIF2 mutations have a synergistic effect on telomere elongation and chromosome loss}

One possible explanation for the strong effect of the rif2 mutation on silencing only when present together with a rif1 mutation is that rif2 significantly exacerbates the telomere elongation effect of rif1 mutations (Hardy et al. 1992b). Extreme telomere elongation (caused by rap $1^{t}$ mutations) can increase TPE in wild-type cells (Kyrion et al. 1993) while exerting an opposite effect on silencing at HMR (Buck and Shore 1995). We therefore examined the length of the telomeric repeats in rif2 and rif1 rif2 double mutant cells. As shown in Figure 4, deletion of RIF2 alone results in an increase of $\sim 100 \mathrm{bp}$ in the average length of $Y^{\prime}$-containing telomeres (which yield the broad lower band in the XhoI digest shown). For comparison, a RIF1 deletion resulted in a somewhat greater increase in average length and heterogeneity of telomeres, as shown previously (Hardy et al. 1992b). In DNA from cells lacking both RIF1 and RIF2, the length of the telomeric repeat sequences is increased by at least $600 \mathrm{bp}$, and up to $2.5 \mathrm{~kb}$ (Fig. 4), which is considerably greater than the increase for either single RIF mutant. Thus, Riflp and Rif $2 p$ probably perform different functions in telomere length regulation.

The fact that the telomere elongation observed in severe rap $1^{s}$ mutants (which are unable to interact with

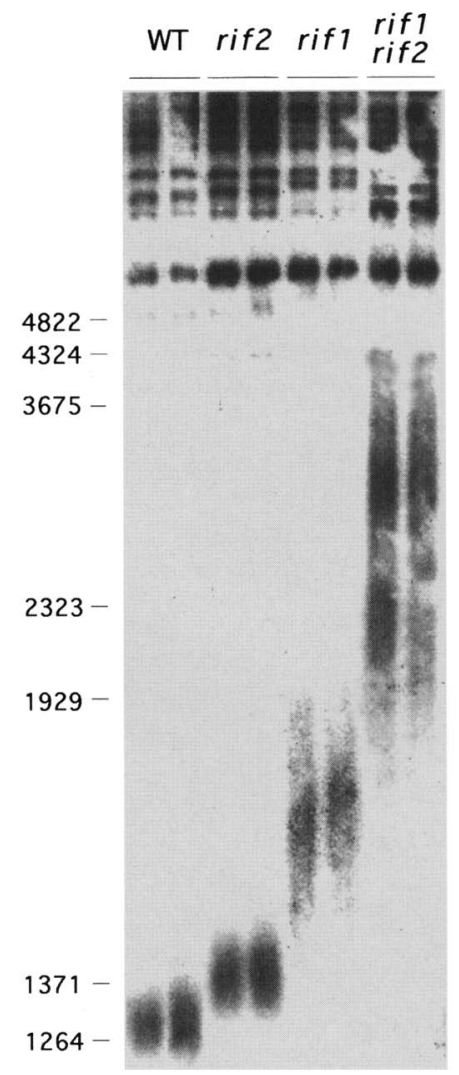

Figure 4. Increased telomere length in RIF-mutant cells. DNA was isolated from wild-type, rif1, rif2, and rif1 rif2 cells (YDW76, YDW123, YDW 77, and YDW124) and was digested with $X$ hoI and hybridized to reveal telomere repeat sequences, as described in Materials and Methods. In wild-type cells, this digest releases a broad band of $\sim 1.2 \mathrm{~kb}$ containing the telomeric repeat sequences from the majority of telomeres (see Zakian 1995a). The relevant genotypes are indicated above the lanes.

Riflp in two-hybrid assays) is similar to that seen in rif1 cells suggests that this allele of RAP1 retains some ability to regulate telomere length. Consistent with this, we found that Rif $2 p$ is able to interact with rap $1^{s}$ mutants in the two-hybrid assay (data not shown). However, this interaction was reduced to $\sim 50 \%$ of that seen with wildtype Raplp fusions, indicating that the rap $1^{s}$ mutations do not specifically affect the Raplp-Rif1p interaction, but instead may be having a more general effect on the carboxy-terminal region of Raplp. This reduced rap $1^{\mathrm{s}} \mathrm{p}-$ Rif $2 p$ interaction may explain why rap $1^{s}$ rif 1 double mutants have a more severe telomere elongation phenotype than either single mutant (L. Sussel, S. Buck, and D. Shore, unpubl.). An additional possibility is that some Rif1 protein is recruited to telomeres in rap $1^{s}$ cells via the Rif1p-Rif2p interaction.

As mentioned above, previous work has shown that a large carboxy-terminal truncation of Raplp (in particular the rap $1^{t}$ allele rap1-17, in which amino acids 663-827 are missing) results in a dramatic increase in telomere length (Kyrion et al. 1992). The protein produced by the 


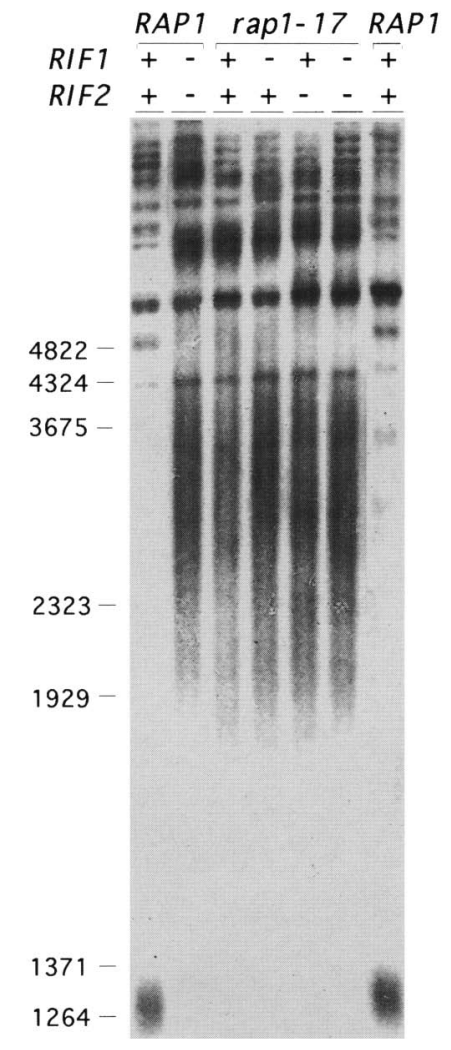

Figure 5. Telomere length in rap1-17 cells and in cells lacking both RIF1 and RIF2. DNA was isolated and treated as in Fig. 4. The genotypes of the cells are shown at the top. $(+)$ Wild type; $(-)$ mutant for RIF1 or RIF2 as shown. The RAP1 alleles were either wild-type or rap1-17, which expresses a Rap1 protein lacking the carboxy-terminal 164 amino acids. The strains used in this analysis (YDW126-YDW131) were generated by sporulation and dissection of the diploid YDW125, which is heterozygous for the rap1-17 allele and disruptions of both RIF1 and RIF2.

rap1-17 allele would be unable to interact with either Rif $1 \mathrm{p}$ or Rif $2 \mathrm{p}$, as judged by our two-hybrid analyses (Hardy et al. 1992b; Fig. 1). It was therefore of interest to determine whether the changes in telomere length in a rif1 rif2 double mutant are comparable to those seen in a rap1-17 strain. To compare these strains more easily we crossed a rap1-17 strain with a strain mutated for both RIF1 and RIF2 to create a diploid that was heterozygous for each mutation. This diploid was sporulated to obtain strains with combinations of these three mutations. As shown in Figure 5, a similar increase in telomere length and heterogeneity is observed when Raplp is truncated or when both RIF1 and RIF2 are mutated. Additionally, no further increase in telomere length was observed in cells carrying the rap1-17 allele in combination with mutations in RIF1 and RIF2 (Fig. 5). These results indicate that the Raplp carboxyl terminus and the Rif1/Rif2 protein pair act in the same pathway to regulate telomere length. In other words, the function of the Raplp carboxyl terminus can be explained, at least in principle, by its ability to recruit Rif $1 p$ and Rif $2 p$ to the telomere.
To further address the functional relationships between Rif1p, Rif2p, and the Raplp carboxyl terminus, we measured chromosome loss rates in RIF single mutants and the rif1 rif2 double mutant. Previous studies have shown that rap $1^{t}$ mutants display elevated chromosome loss rates, perhaps as a result of impaired telomere function (Kyrion et al. 1992). As shown in Table 5, we found that chromosome III loss rates in rif1 and rif2 mutants were elevated by $\sim 7.5$ - and 3.5-fold, respectively, compared with wild-type. However, just as for silencing and telomere length measurements, the rif1 rif2 double mutant displayed a synergistic effect, giving a chromosome III loss rate $>30$-fold greater than wild type. This relative increase is comparable to that determined for the most severe rap $1^{t}$ mutant (rap1-17) using a different chromosome loss assay (Kyrion et al. 1992).

Additionally, cells mutated for both RIF1 and RIF2 have a significantly longer doubling time than wild-type cells (Table 5). In contrast, mutation of either RIF gene alone does not significantly alter the growth rate, providing further evidence for synergistic action of Riflp and Rif2p.

\section{Overexpression of Rif $1 p$ and Rif $2 p$ reduces telomere length and reverses the effect of Rap $1 p$ carboxy-terminal overexpression}

It has been demonstrated previously that overexpression of the carboxyl terminus of Raplp, in the absence of its DNA-binding domain, increases telomere length (Conrad et al. 1990; Hardy 1991). The likely explanation of this effect is that the overexpressed carboxyl terminus of Raplp interacts with proteins involved in telomere length regulation, titrating them away from the telomeres and thus causing telomere elongation. We reasoned that if Riflp and Rif $2 p$ were responsible for telomere length regulation, and in particular acted as negative regulators of telomere elongation, overexpression of these proteins might shorten telomeres in wild-type cells and restore normal telomere length to cells in which the carboxyl terminus of Raplp is overexpressed. As shown in Figure 6 (lanes 2,3), the telomeric repeats in

Table 5. Phenotypes of cells lacking Rif1p and Rif2p

\begin{tabular}{lccc}
\hline Genotype & $\begin{array}{c}\text { Telomere length } \\
\text { increase }^{\mathrm{b}} \\
\text { (bp) }\end{array}$ & $\begin{array}{c}\text { Doubling } \\
\text { time }^{\mathrm{c}} \\
\text { (min) }\end{array}$ & $\begin{array}{c}\text { Chromosome } \\
\text { loss rate }^{\mathrm{d}} \\
\text { (per generation) }\end{array}$ \\
\hline Wild type & N.A. & 90 & $4.3 \times 10^{-7}$ \\
rif1 & $200-600$ & 92 & $3.2 \times 10^{-6}$ \\
rif2 & 100 & 90 & $1.5 \times 10^{-6}$ \\
rif1 rif2 & $600-2500$ & 108 & $1.5 \times 10^{-5}$ \\
\hline
\end{tabular}

${ }^{a}$ All strains are isogenic to W303 except for the RIF mutations indicated.

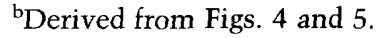

${ }^{\mathrm{c}}$ Growth rates were measured for exponentially growing cells in rich medium (YPD) at $30^{\circ} \mathrm{C}$.

${ }^{\mathrm{d}}$ Based on determination of rate of loss of chromosome III (see Materials and Methods for details). 


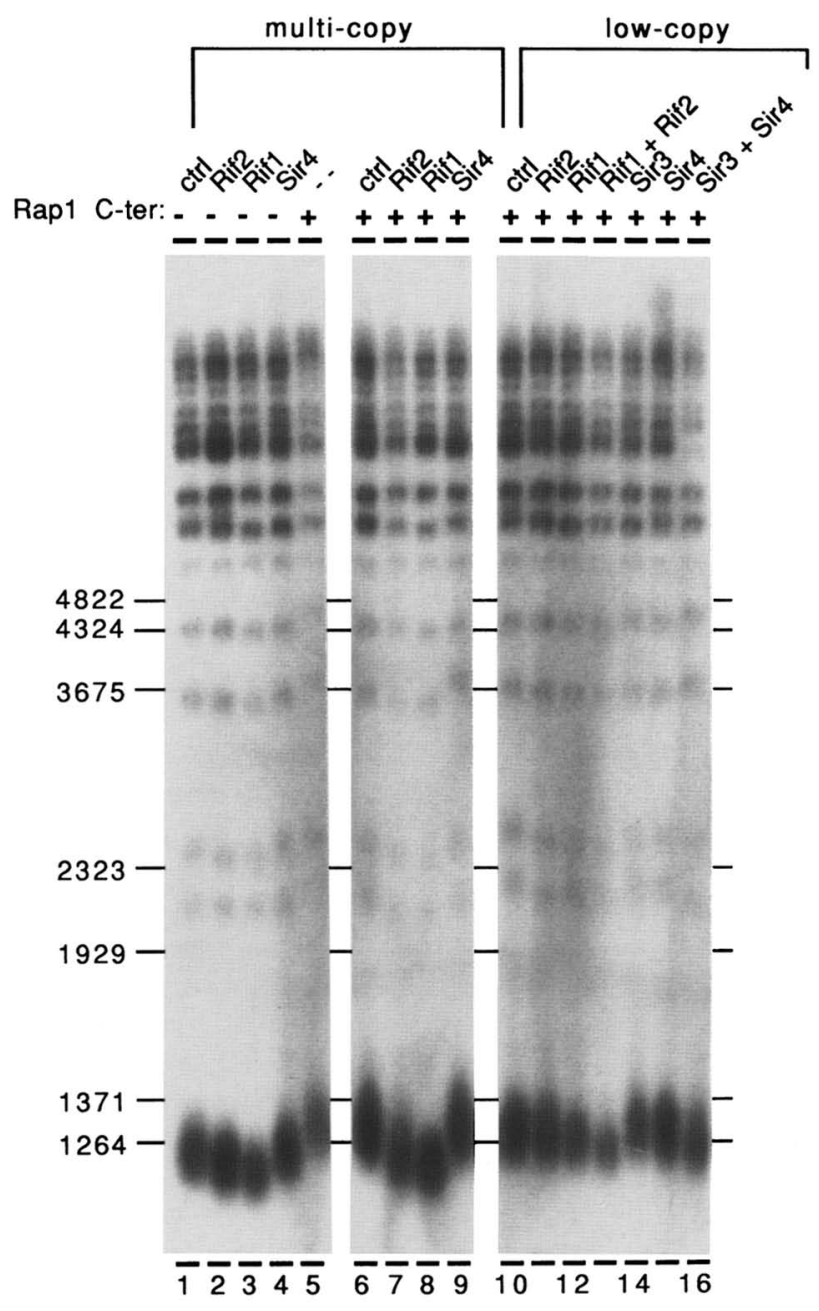

Figure 6. Effects of overexpression of Riflp and Rif2p on telomere length. Wild-type W303-1B cells (MATa) were transformed with plasmids containing the genes encoding the proteins indicated at the top. Rif $1 p$, Rif $2 p$, Sir $3 p$, and Sir $4 p$ were expressed as full-length proteins from their own promoters, present on either multicopy ( $2 \mu$-based) or low-copy (CEN/ARS-based) plasmids. (ctrl) The presence of a control plasmid lacking an insert. (Rapl C-ter) The presence $(+)$ of a plasmid encoding amino acids 630 827 of Raplp fused to LexA. This fusion, which lacks the Raplp DNA-binding domain, is expressed from the strong $A D H 1$ promoter on a multicopy $(2 \mu)$ plasmid. DNA was prepared and telomere repeat lengths analyzed as in Fig. 4.

wild-type cells carrying either full-length RIF2 or RIF1 on a multicopy plasmid were reduced in length. No effect of a multicopy SIR4-containing plasmid was observed (Fig. 6, lane 4). In contrast, cells expressing LexA/ Rap1(630-827) from the strong $A D H 1$ promoter (on a multicopy plasmid) had slightly elongated telomeres (Fig. 6, lane 5), consistent with previous studies (Conrad et al. 1990; Hardy 1991). Strikingly, overexpression of either RIF1 or RIF2, but not SIR4, resulted in a reduction in telomere length in the presence of LexA/Rapl/630827) (Fig. 6, lanes 6-9). The RIF1 high-copy plasmid sig- nificantly reduced telomere lengths to nearly wild-type levels, whereas RIF2 had a small effect.

We also examined the effect on telomere length of the addition of single extra copies of the RIF and SIR genes in the presence of carboxy-terminal overexpression of Raplp. The addition of RIF1 on a centromere-based plasmid was able to partially suppress the effect of the LexA/ Rap1(630-827) plasmid. Strikingly, when RIF1 and RIF2 were present together on centromeric plasmids in these cells, a reduction in telomere length and heterogeneity almost to that of wild-type cells was observed (Fig. 4, lanes 10-13). No effect of either SIR3 or SIR4 alone was observed, although some suppression of telomere elongation was observed with both together (Fig. 6, lanes 1416). Taken together, these results suggest that the levels of Rif $1 p$ and Rif $2 p$ can have a direct effect on the regulation of telomere length, and provide further indication that these two proteins play a critical role in this process.

\section{Discussion}

Several lines of evidence indicate that Raplp, which binds to multiple high-affinity sites within the poly $\left(\mathrm{C}_{1-3} \mathrm{~A}\right)$ tracts at telomeres, plays a critical yet complex role in telomere length regulation. Temperature-sensitive RAP1 mutants, grown under semi-permissive conditions, have shorter telomeres (Conrad et al. 1990; Lustig et al. 1990), suggesting that one function of Raplp may be simply to protect the telomere from degradation by exonucleases. However, this is unlikely to be the sole function of Raplp in telomere length regulation. Lustig and colleagues have shown that carboxy-terminal truncation mutations of RAP1, which retain the DNA-binding domain and are viable, exhibit an extreme telomereelongation phenotype (Kyrion et al. 1992). It is presumed, therefore, that this nonessential domain of Raplp, which is also required for telomere position effect and $H M$ locus silencing (Kyrion et al. 1993; Moretti et al. 1994), negatively regulates telomere elongation. This might occur, for example, by direct inhibition of telomerase or by controlling the access of telomerase to the chromosome end. Whatever the mechanism of telomere length regulation by Raplp, it is likely to work through interactions with other proteins because overexpression of the Raplp carboxyl terminus, in the absence of its normal DNAbinding domain, results in telomere elongation (Conrad et al. 1990; Hardy 1991). These data can be most easily explained by the existence of titratable factors that interact with the Rap1p carboxyl terminus to mediate telomere length regulation. The first candidate for such a factor to be identified was Riflp (Raplp-interacting factor 1), which was isolated by a two-hybrid screen using the carboxy-terminal 175 amino acids of Rap $1 p$ (Hardy et al. 1992b|. However, the effect on telomere length of mutating RIF1 is relatively small by comparison with the Raplp truncation mutants.

Rif $1 p$ and Rif $2 p$ are required to mediate the telomere length regulation function of Rap1p

Here we have described a new Raplp-interacting factor 
(Rif2p) with properties very similar to those of Riflp. Both of these proteins interact with the Raplp carboxyl terminus in two-hybrid assays, and mutation of either protein results in moderate telomere elongation and an increase in TPE. Significantly, cells lacking both of these proteins have extremely elongated telomeres that are indistinguishable from those in cells containing a rap $1^{t}$ mutation, which removes the Raplp carboxyl terminus. The simplest interpretation of these observations is that the Raplp carboxyl terminus recruits both Riflp and Rif $2 p$ to telomeres where they are required to regulate telomere elongation. One prediction of this model, which we are at present trying to test, is that Rif proteins are localized at telomeres in vivo. Our results do not indicate whether or not Rif $1 p$ and Rif $2 p$ are sufficient to mediate the telomere length regulation function of Raplp, but they do indicate that both are necessary. If other Rifs are involved in this regulatory function, their action must be dependent upon either RIF1, RIF2, or both. Finally, the fact that neither RIF1 nor RIF2 mutation exacerbates the telomere elongation phenotype of the rap1-17 allele suggests that the function of these two proteins in telomere length regulation requires the Raplp carboxyl terminus.

Because Rif $1 p$ and Rif2p can interact with each other in the two-hybrid system, these two proteins may act as a complex that is recruited to the telomere. If this is the case, it might seem odd that the two proteins have distinct functions, as indicated by the synergistic effect of a rif1 rif2 double mutation on telomere length. One possible explanation for these observations is that, once recruited to the telomere, Riflp and Rif2p interact with different proteins, and thus genetically and biochemically define two regulatory pathways for telomere length regulation. Alternatively, Rif $1 p$ and Rif $2 p$ might have a common target. In this case each protein would by itself provide partial regulation by interacting independently with this target. More information concerning the mechanism of action of both proteins will be required before these models can be distinguished. Another interesting possibility raised by the interaction of Riflp with Rif $2 p$ is that Riflp at one telomere may interact with Rif $2 p$ at another. Thus, the Rif proteins may play a role in the clustering of telomeres into groups that has been observed by immunolocalization of telomere-associated proteins and in situ hybridization with telomere-specific probes (Klein et al. 1992; Palladino et al. 1993; Gotta et al. 1996). Finally, we should point out that it is unclear at present what, if any, role Rif 1 and Rif 2 might play in a novel mechanism of telomere length control, called "telomeric rapid deletion" (Li and Lustig 1996), which can reduce extremely elongated telomeres to wild-type lengths in what appears to be a single-division event.

\section{Rif and Sir proteins mediate different functions of Rap1p at telomeres}

Because the initial characterization of RIF1 revealed a complex set of effects on telomeric and HM locus silencing as well as telomere length control (Hardy et al. 1992b; Kyrion et al. 1993), the precise function of this protein was unclear. The identification and characterization of Rif $2 p$ reported here greatly clarifies this picture by providing evidence for a specialized mechanism of telomere length regulation by Raplp, separate from its silencing function. The fact that Rif $2 p$ is required together with Rif1p for telomere length control, and that these two proteins interact with each other in two-hybrid assays, supports the idea that their primary role is to negatively regulate telomere elongation. Several lines of evidence indicate that the changes in silencing brought about by RIF mutations are likely to be secondary consequences of their effects on telomere length and structure. To begin with, telomere elongation in wild-type cells is sufficient to cause increased TPE (Kyrion et al. 1993) and decreased silencing at HMR (Buck and Shore 1995). In principle, therefore, the effects of RIF mutations on silencing could be an indirect consequence of their effects on telomere structure. Second, Rif proteins, unlike the Sir proteins, are not required for silencing, but rather affect the balance between telomeric and $H M R$ locus silencing mediated by competition for Sir proteins (Buck and Shore 1995). As such, the Rif proteins can be viewed as regulators of silencing, but are not required components of silent chromatin, like Sir3p and Sir $4 p$ (Hecht et al. 1995, 1996). Finally, it is important to keep in mind that the effects of SIR3 and SIR4 mutations on telomeres are exactly opposite those of RIF1 and RIF2 mutations. In the SIR mutants TPE is abolished (Aparicio et al. 1991) and telomere tracts become slightly shorter (Palladino et al. 1993), whereas RIF mutations improve TPE (Fig. 3B; Kyrion et al. 1993) and increase telomere length (Fig. 4; Hardy et al. 1992b).

In a separate report (Marcand et al. 1997) we present evidence that telomere length is regulated by a negative feedback mechanism that can sense the precise number of Rapl carboxyl termini at the chromosome end. The data presented here suggest that the Rif1p/Rif2p complex, bound to Raplp at telomeres, mediates this lengthsensing and regulation function of Raplp, which is itself antagonized by Raplp-Sir interactions. Putting these and other data together, we propose a model in which Raplp-Sir and Raplp-Rif complexes are naturally partitioned to opposite ends of the telomeric $\mathrm{C}_{1-3} \mathrm{~A}$ repeats (see Fig. 7). We imagine that Raplp-Sir interactions are favored at the proximal end of the telosome (Wright et al. 1992) (the telosome/nucleosome junction) by cooperative interactions between Sir proteins themselves (Moretti et al. 1994) and between Sir proteins and histones H3 and H4 (Hecht et al. 1995). Because TPE is likely to result from a continuous spreading of Sir complexes along the nucleosome fiber, it follows that the Raplp molecules at the junction between the telosome and nucleosomal DNA would be most critical for establishing silencing. On the other hand, the Riflp/Rif2p complex is likely to act at the telomere end, and we speculate that Rif protein assembly at the distal end of the telosome might be promoted by interactions with telomere endbinding proteins. We note that a tendency of Rif complexes to assemble at the distal end of the telomere 

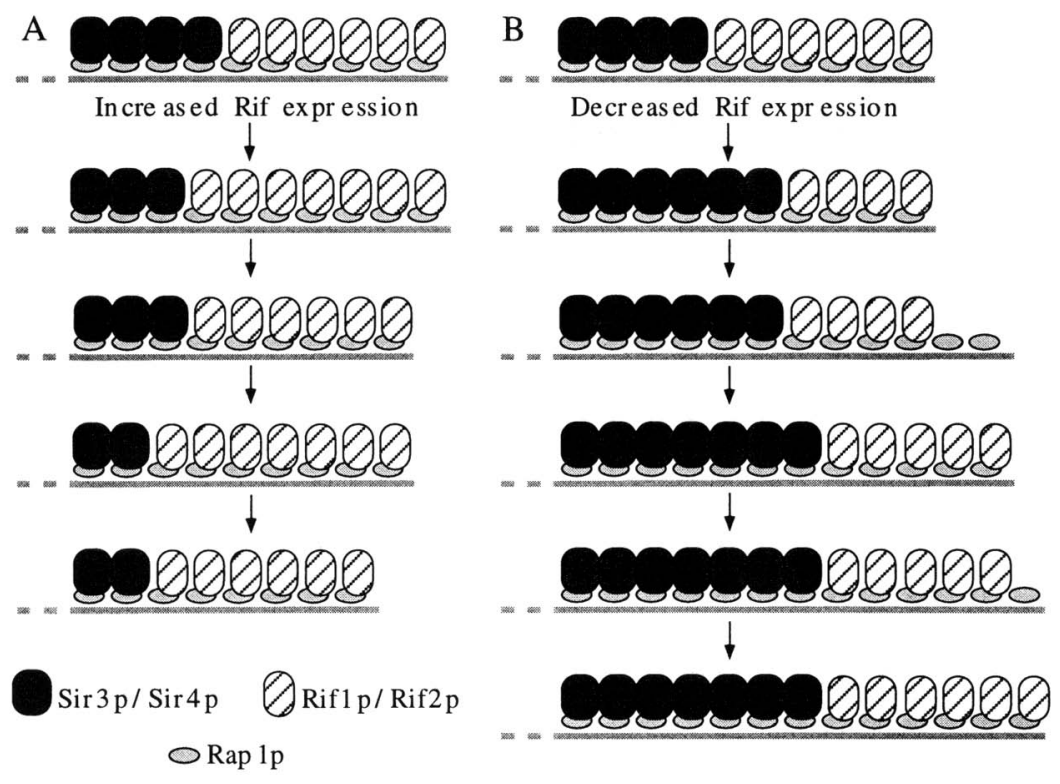

Figure 7. A speculative model for the arrangement of Rif and Sir protein complexes at telomeres. Partitioning of the telosome (Wright et al. 1992) into centromere-proximal Sir and telomere-proximal Rif domains is diagramed, together with the effects of increased $(A)$ and decreased $(B)$ expression of Rif proteins. We propose that the extent of the Raplp-Rif protein complex may play a direct role in regulating telomere length. In the case of Rif protein overexpression we imagine that Rif complex spreads from the telomere end and results in a gradual shortening of the $\mathrm{C}_{1-3} \mathrm{~A}$ tract until a new stable equilibrium value is reached in which Rif complex addition and telomere shortening are in balance. Under conditions of decreased Rif expression we propose a loss of Rif complex at the telosome and a corresponding increase in Sir complex (which results in improved TPE). This reduction of Rif complex results in telomere elongation, which, depending upon the severity of the defect, may lead to a longer, stable telomere length (rif1 or rif2 single mutants) or essentially unregulated telomere elongation (rif1 rif2 double mutant). might help to explain recent observations in Kluyveromyces lactis that suggest that Raplp-binding sites nearest to the telomere end play a critical role in length regulation (Krauskopf and Blackburn 1996). Nevertheless, we would emphasize that this model is speculative, and that the available data do not rule out a model in which Sir and Rif complexes are interdigitated along the telosome. It seems likely that a direct biochemical and structural characterization of the telosome will be required to distinguish between these two models.

Whatever the precise arrangement of Sir and Rif complexes along the telosome, the critical parameter controlling telomere length regulation would appear to be the amount of Rif complex assembled there. The shortening of telomeres caused by the overexpression of Rif proteins (Fig. 6) would thus result from an extension of the Rif complex along the telosome that results in telomere shortening, possibly by inhibition of telomerase (Fig. 7A). Conversely, mutation of one of the RIF genes may result in a decrease in the amount of the telomere bound by Rif protein, allowing telomerase activation and telomere elongation (Fig. 7B). The removal of Sir3p or Sir4p by mutation would allow free access of the Rifl/ Rif 2 complex to the telosome, which would cause increased telomerase inhibition and result in telomere shortening, which is precisely what has has been observed (Palladino et al. 1993). Our model for telomere length regulation (Marcand et al. 1997) predicts that the extent of telomere shortening in SIR3 or SIR4 mutants $(\sim 50 \mathrm{bp})$ would reflect the amount of $\mathrm{C}_{1-3} \mathrm{~A}$ tract occupied by Rap1p-Sir complexes (thus excluding Rif1/Rif2) in wild-type cells. Assuming that Raplp binding sites occur approximately every $18 \mathrm{bp}$ along the telomere, this would translate to about three Raplp-Sir complexes.

\section{How do Rif proteins regulate telomere length?}

Our data can be most simply explained by proposing that Rif proteins are recruited to telomeres by Raplp where they either block telomere elongation directly or promote degradation of the ends. To explain how this regulatory mechanism can be highly sensitive to the number of Raplp molecules (and ultimately Rif complexes) bound at an end, we would propose that either a stochastic process controls events at the end through interactions with a Rap1p/Rif complex, as suggested previously for the yeast K. lactis (McEachern and Blackburn 1995), or the Raplp/Rif complex creates a length-sensitive switch to control the access of factors to the telomere end or their activity once bound there (Marcand et al. 1997). One obvious candidate for Rif action is the telomerase enzyme itself, which has been detected recently in vitro (Cohn and Blackburn 1995; Lin and Zakian 1995), and whose RNA template is now known (Singer and Gottschling 1994). Another candidate for Rif action is the product of the PIF1 gene, a helicase that inhibits telomere elongation (Schulz and Zakian 1994). One could imagine that Rif proteins target this enzyme to telomeres. However, genetic epistasis tests suggest that Piflp acts in a different pathway from the Raplp carboxyl terminus (Schulz and Zakian 1994). Alternatively, the Rif proteins may interact with one or more recently identified telomere end-binding proteins to regulate telomerase. The Est1 (Virta-Pearlman et al. 1996) and Cdc13(Est4) (Lin and Zakian 1996; Nugent et al. 1996) proteins both bind to single-strand $\mathrm{TG}_{1-3}$ telomeric sequences and appear by genetic criteria to be essential regulators of telomerase activity (Lundblad and Szostak 1989; Garvik et al. 1995; Nugent et al. 1996). A newly 
identified Cdcl3p-interacting protein with similar functions, Stnlp, is another potential Rif target (Grandin et al. 1997). Given our present limited understanding of telomere replication, it seems likely that there are other possible mechanisms of Rif1 action. Identifying factors other than Raplp that interact with the Rif proteins, and studying genetic and biochemical interactions between the RIF genes and known telomere replication factors, should provide important clues to understanding how the Rif proteins work.

\section{Materials and methods}

Plasmids

All LexA fusions were expressed from pBTM116 (2 $\mu \mathrm{m}$ origin, TRP1, pADH1-lexA; a gift of P. Bartel and S. Fields, State University of New York, Stony Brook|. The LexA/Rapl fusions are as described previously (Moretti et al. 1994), except for LexA/ Rap 1(679-756), which was created by PCR. The GAD-fusion library screened with LexA/Rapl was created in pGAD3/Chien et al. 1991) and was a generous gift of P. Bartel and S. Fields. $\mathrm{GAD} /$ rif2fs was created by digesting GAD/Rif2 with MluI, endfilling with Klenow, and religating. LexA/Rif2 fusions were generated by PCR, except for those encoding amino acids 18-389 and 18-298, which were created by subcloning fragments from GAD/Rif2 into pBS (Stratagene), then into pBTM116. GAD/ Rapl encoded amino acids $478-827$ and was isolated by screening a two-hybrid library with LexA/Rif2(2-395). The Gbd/Rap1 fusions, GAD/Rif1, GAD/Sir3, and GAD/Sir4, are as described previously (Hardy et al. 1992a; Moretti et al. 1994). Wild-type RIF1, RIF2, SIR3, and SIR4 were expressed from their own promoters, and were present on CEN/ARS- or 2- $\mu$-based pRS vectors (Sikorski and Hieter 1989). The full-length RIF2 gene, including $495 \mathrm{bp}$ of sequence $5^{\prime}$ to the initiation codon and $120 \mathrm{bp}$ $3^{\prime}$ to the translational stop, was isolated by PCR and cloned into pBS. The RIF2 deletion/insertion mutation was created in pBS by replacing the sequences encoding amino acids 18-389 with the HIS 3 gene. RIF1, SIR3, and SIR4 disruption mutations have been described previously (Hardy et al. 1992b; Moretti et al. 1994). Sequences of oligonucleotides used in PCR-based cloning steps and details of all plasmid constructs are available upon request.

\section{Yeast strains}

The yeast strains used in this study are all derivatives of either W303 (Thomas and Rothstein 1989) or the two-hybrid assay strain CTY10-5D, and are listed in Table 6.

\section{Yeast manipulations}

Growth and manipulation of yeast strains was carried out using standard procedures (Rose et al. 1990). Screening of the GADfusion library with LexA/Rap1 was carried out in CTY10-5D, as described previously (Moretti et al. 1994). Spot assays were performed by spotting $5 \mu \mathrm{l}$ aliquots of 10 -fold serial dilutions of a saturated overnight culture onto plates containing the appropriate selective media. Plates were photographed after 2-3 days.

Table 6. Yeast strains used in this study

\begin{tabular}{|c|c|}
\hline W303-1A & HML $\alpha$ MATa HMRa ade2-1 can1-100 his3-11,15 leu2-3,112 trp1-1 ura3-1 \\
\hline W303-1B & HML $\alpha$ MAT $\alpha$ HMa ade2-1 can1-100 his3-11,15 leu2-3,112 trp1-1 ura3-1 \\
\hline CTY10-5D & MATa ade2-1 trp1-901 leu2-3,112 his3-200 gal4 gal80 URA3::LexA op-lacZ \\
\hline PM101 & CTY10-5D sir3::HIS3 \\
\hline PM102 & CTY10-5D sir4::HIS3 \\
\hline PM103 & CTY10-5D rif $1:: H I S 3$ \\
\hline AJL394-1a & W303-1A rap1-17 telVII::ADE2/URA3 \\
\hline YLS607 & W303-1B hmri $\triangle A:: A D E 2$ rif1::URA3 \\
\hline YDW62 & CTY10-5D rif2::HIS3 \\
\hline YDW76 & W303-1B hmr $\Delta A:: T R P 1$ telVII::URA3 \\
\hline YDW77 & YDW76 rif2::HIS3 \\
\hline YDW123 & YDW76 rif1::URA3 \\
\hline YDW124 & YDW76 rif1::URA3 rif2::HIS3 \\
\hline YDW80 & W303 $\frac{H M L \alpha M A T \mathbf{a} h m r \Delta A:: A D E 2}{H M L \alpha M A T \alpha h m r \Delta A: \because A D E 2}$ \\
\hline YDW81 & YDW80 rif1::URA3/rif1::URA3 \\
\hline YDW82 & YDW80 rif2::HIS3/rif2::HIS3 \\
\hline YDW83 & YDW80 rif1::URA3/rif1::URA3 rif2:: HIS3/rif2::HIS3 \\
\hline YDW84 & W303-1A hmr $\triangle A::$ TRP1 telVII::ADE2/URA3 \\
\hline YDW85 & YDW84 rif1::URA3 \\
\hline YDW86 & YDW84 rif2::HIS3 \\
\hline YDW87 & YDW84 rif $1:: U R A 3$ rif2::HIS3 \\
\hline YDW125 & W303 $\frac{H M L \alpha M A T a \text { hmr } \Delta A:: T R P 1 \text { rap } 1-17 \text { rif1::URA3 rif2::HIS3 }}{H M L \alpha M A T \alpha H M R \mathbf{R A P 1} \text { RIF1 RIF2 }}$ \\
\hline YDW126 & W303-1A $h m r \Delta A:: T R P 1$ \\
\hline YDW127 & W303-1A rap1-17 \\
\hline YDW128 & YDW127 rif1::URA3 \\
\hline YDW129 & YDW 127 rif2::HIS3 \\
\hline YDW130 & YDW127 rif1 ::URA3 rif2::HIS3 \\
\hline YDW 131 & YDW126 rif1::URA3 rif2::HIS3 \\
\hline
\end{tabular}


$\beta$-galactosidase assays were carried out as described previously (Moretti et al. 1994).

\section{Chromosome loss assays}

Determination of the rate of loss of chromosome III was carried out as described previously (Chi and Shore 1995). Briefly, single colonies were resuspended in $1 \mathrm{ml}$ of YPD and sonicated. Dilutions were plated onto YPD medium to assess the number of viable cells. Half of each colony was then incubated with a 100 -fold excess of a MATa tester strain for $8 \mathrm{hr}$ at $30^{\circ} \mathrm{C}$. Cells were then spread onto SD plates to select for colonies that arose from a mating event. The chromosome rate loss was derived according to the following formula: $(0.4343 \times F) / \log N-\log N_{0}$, where $F=$ the frequency of mating events, $N=$ the number of cells in the colony and $N_{0}=$ the number of cells from which the colony arose. For this analysis, we used diploid strains that lacked any mating-type information at $H M R$.

\section{DNA sequencing}

All sequencing was carried out by use of the dideoxy chain termination method, using Sequenase (Amersham).

\section{Telomere blots}

DNA was isolated from overnight yeast cultures and $1 \mu \mathrm{g}$ was digested with $X$ hoI for $4 \mathrm{hr}$. DNA was electrophoresed through $0.8 \%$ agarose and transferred to nylon membranes (Hybond). Membranes were hybridized at $50^{\circ} \mathrm{C}$ in $6 \times$ SSC, $5 \times$ Denhardt's solution, with a poly[d(G-T)] probe labeled by random priming. Membranes were washed twice in $2 \times \mathrm{SSC}$ at $55^{\circ} \mathrm{C}$ for $45 \mathrm{~min}$ and autoradiographed with Kodak X-AR5 film.

\section{Acknowledgments}

We are grateful to A. Lustig for providing strains and to P. Bartel and S. Fields for generously providing the pGAD3 library. We would also like to thank H. Laman, L. Pemberton, D. Vannier, and S. Marcand for critical discussion and helpful suggestions; S. Marcand for sharing unpublished results and ideas; and R. Rothstein for the use of tetrad dissection microscopes. This work was supported by grants from the National Institutes of Health (GM40094) and the American Cancer Society (VM-62) to D.S. D.W. was a recipient of a long-term fellowship from the Human Frontiers in Science Program.

The publication costs of this article were defrayed in part by payment of page charges. This article must therefore be hereby marked "advertisement" in accordance with 18 USC section 1734 solely to indicate this fact.

\section{References}

Aparicio, O.M., B.L. Billington, and D.E. Gottschling. 1991. Modifiers of position effect are shared between telomeric and silent mating-type loci in S. cerevisiae. Cell 66: 12791287.

Blackburn, E.H. 1994. Telomeres: No end in sight. Cell 77: 621623.

Buchman, A.R., N.F. Lue, and R.D. Kornberg. 1988. Connections between transcriptional activators, silencers, and telomeres as revealed by functional analysis of a yeast DNAbinding protein. Mol. Cell. Biol. 8: 5086-5099.

Buck, S.W. and D. Shore. 1995. Action of a RAP1 C-terminal silencing domain reveals an underlying competition be- tween HMR and telomeres in yeast. Genes and Dev. 9: 370384.

Chi, M.-H. and D. Shore. 1995. SUM1-1, a dominant suppressor of $S I R$ mutations in Saccharomyces cerevisiae, increases transcriptional silencing at telomeres and HM mating-type loci and decreases chromosome stability. Mol. Cell. Biol. 16: 4281-4294.

Chien, C.-T., P.L. Bartel, R. Sternglanz, and S. Fields. 1991. The two-hybrid system: A method to identify and clone genes for proteins that interact with a protein of interest. Proc. Natl. Acad. Sci. 88: 9578-9582.

Cockell, M., F. Palladino, T. Laroche, G. Kyrion, C. Liu, A.J. Lustig, and S.M. Gasser. 1995. The carboxy termini of Sir4 and Rap1 affect Sir3 localization: Evidence for a multicomponent complex required for yeast telomeric silencing. $I$. Cell Biol. 129: 909-924.

Cohn, M. and E.H. Blackburn. 1995. Telomerase in yeast. Science 269: 396-400.

Conrad, M.N., J.H. Wright, A.J. Wolf, and V.A. Zakian. 1990. RAP1 protein interacts with yeast telomeres in vivo: Overproduction alters telomere structure and decreases chromosome stability. Cell 63: 739-750.

Drazinic, C.M., J.B. Smerage, M.C. Lopez, and H.V. Baker. 1996. Activation mechanism of the multifunctional transcription factor Repressor-Activator Protein 1 (Raplp). Mol. Cell. Biol. 16: 3187-3196.

Garvik, B., M. Carlson, and L. Hartwell. 1995. Single-stranded DNA arising at telomeres in $c d c 13$ mutants may constitute a specific signal for the RAD9 checkpoint. Mol. Cell. Biol. 15: 6128-6138.

Gilson, E., M. Roberge, R. Giraldo, D. Rhodes, and S.M. Gasser. 1993. Distortion of the DNA double helix by RAP1 at silencers and multiple telomeric binding sites. J. Mol. Biol. 231: 293-310.

Gotta, M., T. Laroche, A. Formenton, L. Maillet, H. Scherthan, and S.M. Gasser. 1996. The clustering of telomeres and colocalization with Rap1, Sir3, and Sir4 proteins in wild-type Saccharomyces cerevisiae. I. Cell Biol. 134: 1349-1363.

Grandin, N., S.I. Reed, and M. Charbonneau. 1997. Stn1, a new Saccharomyces cerevisiae protein, is implicated in telomere size regulation in association with $\mathrm{Cdc} 13$. Genes \& Dev. 11: $512-527$.

Greider, C.W. 1996. Telomere length regulation. Annu. Rev. Biochem. 65: 337-365.

Hardy, C.F.J. 1991. "Studies on RAPl and the RAP1 interacting factor, RIF1." Ph.D. thesis, Columbia University, New York, NY.

Hardy, C.F.J., D. Balderes, and D. Shore. 1992a. Dissection of a carboxy-terminal region of the yeast regulatory protein RAP1 with effects on both transcriptional activation and silencing. Mol. Cell. Biol. 12: 1209-1217.

Hardy, C.F.J., L. Sussel, and D. Shore. 1992b. A RAP1-interacting protein involved in silencing and telomere length regulation. Genes \& Dev. 6: 801-814.

Hecht, A., T. Laroche, S. Strahl-Bolsinger, S.M. Gasser, and M. Grunstein. 1995. Histone H3 and H4 N-termini interact with SIR3 and SIR4 proteins: A molecular model for the formation of heterochromatin in yeast. Cell 80: 583-592.

Hecht, A., S. Strahl-Bolsinger, and M. Grunstein. 1996. Spreading of transcriptional repressor SIR3 from telomeric heterochromatin. Nature 383: 92-96.

Ivy, J.M., A.J.S. Klar, and J.B. Hicks. 1986. Cloning and characterization of four SIR genes from Saccharomyces cerevisiae. Mol. Cell. Biol. 6: 688-702.

Klein, F., T. Laroche, M.E. Cardenas, J.F.-X. Hofmann, D. Schweizer, and S.M. Gasser. 1992. Localization of RAP1 and 
topoisomerase II in nuclei and meiotic chromosomes of yeast. J. Cell Biol. 117: 935-948.

Krauskopf, A. and E.H. Blackburn. 1996. Control of telomere growth by interactions of RAP1 with the most distal telomeric repeats. Nature 383: 354-357.

Kurtz, S. and D. Shore. 1991. The RAP1 protein activates and silences transcription of mating-type genes in yeast. Genes \& Dev. 5: 616-628.

Kyrion, G., K.A. Boakye, and A.J. Lustig. 1992. C-terminal truncation of RAP1 results in the deregulation of telomere size, stability, and function in Saccharomyces cerevisiae. Mol. Cell. Biol. 12: 5159-5173.

Kyrion, G., K. Liu, C. Liu, and A.J. Lustig. 1993. RAP1 and telomere structure regulate telomere position effects in Saccharomyces cerevisiae. Genes \& Dev. 7: 1146-1159.

Li, B. and A.J. Lustig. 1996. A novel mechanism for telomere size control in Saccharomyces cerevisiae. Genes \& Dev. 10: $1310-1326$.

Lin, J.J. and V.A. Zakian. 1995. An in vitro assay for Saccharomyces telomerase requires EST1. Cell 81: 1127-1135.

1996. The Saccharomyces CDC13 protein is a singlestrand TG1-3 telomeric DNA-binding protein in vitro that affects telomere behavior in vivo. Proc. Natl. Acad. Sci. 93: $13760-13765$.

Liu, C., X. Mao, and A.J. Lustig. 1994. Mutational analysis defines a C-terminal tail domain of RAPl essential for telomeric silencing in Saccharomyces cerevisiae. Genetics 138: $1025-1040$.

Longtine, M.S., N.M. Wilson, M.E. Petracek, and J. Berman. 1989. A yeast telomere binding activity binds to two related telomere sequence motifs and is indistinguishable from RAP1. Curr. Genet. 16: 225-240.

Lundblad, V. and J.W. Szostak. 1989. A mutant with a defect in telomere elongation leads to senescence in yeast. Cell 57: 633-643.

Lustig, A.J. and T.D. Petes. 1986. Identification of yeast mutants with altered telomere structure. Proc. Natl. Acad. Sci. 83: 1398-1402.

Lustig, A.J., S. Kurtz, and D. Shore. 1990. Involvement of the silencer and UAS binding protein RAPI in regulation of telomere length. Science 250: 549-553.

Marcand, S., E. Gilson, and D. Shore. 1997. A protein-counting mechanism for telomere length regulation in yeast. Science 275: 986-990.

McEachern, M.J. and E.H. Blackburn. 1995. Runaway telomere elongation caused by telomerase RNA gene mutations. $\mathrm{Na}$ ture 376: 403-409.

Moretti, P., K. Freeman, L. Coodley, and D. Shore. 1994. Evidence that a complex of SIR proteins interacts with the silencer and telomere-binding protein RAP1. Genes \& Dev. 8: 2257-2269.

Nugent, C.I., T.R. Hughes, N.F. Lue, and V. Lundblad. 1996. Cdc13p: A single-strand telomeric DNA-binding protein with a dual role in yeast telomere maintenance. Science 274: 249-252.

Palladino, F., T. Laroche, E. Gilson, A. Axelrod, L. Pillus, and S.M. Gasser. 1993. SIR3 and SIR4 proteins are required for the positioning and integrity of yeast telomeres. Cell 75: 543-555.

Rine, J. and I. Herskowitz. 1987. Four genes responsible for a position effect on expression from $H M L$ and $H M R$ in Saccharomyces cerevisiae. Genetics 116: 9-22.

Rose, M.D., F. Winston, and P. Hieter. 1990. Methods in yeast genetics: A laboratory course manual. Cold Spring Harbor Laboratory Press, Cold Spring Harbor, NY.

Runge, K.W. and V.A. Zakian. 1989. Introduction of extra telo- meric DNA sequences into Saccharomyces cerevisiae results in telomere elongation. Mol. Cell. Biol. 9: 1488-1497.

Sandell, L.L. and V.A. Zakian. 1993. Loss of a yeast telomere: Arrest, recovery and chromosome loss. Cell 75: 729-739.

Schulz, V.P. and V.A. Zakian. 1994. The Saccharomyces PIF1 DNA helicase inhibits telomere elongation and de novo telomere formation. Cell 76: 145-155.

Shampay, J. and E.H. Blackburn. 1988. Generation of telomerelength heterogeneity in Saccharomyces cerevisiae. Proc. Natl. Acad. Sci. 85: 534-538.

Shore, D. 1994. RAPl: A protean regulator in yeast. Trends Genet. 10: 408-412.

-. 1995. Telomere position effect and transcriptional silencing in the yeast Saccharomyces cerevisiae. In Telomeres (ed. E.H. Blackburn and C.W. Greider), pp. 139-191. Cold Spring Harbor Laboratory Press, Cold Spring Harbor, NY.

Shore, D. and K. Nasmyth. 1987. Purification and cloning of a DNA binding protein from yeast that binds to both silencer and activator elements. Cell 51: 721-732.

Sikorski, R. and P. Hieter. 1989. A system of shuttle vectors and yeast host strains designed for efficient manipulation of DNA in Saccharomyces cerevisiae. Genetics 122: 19-27.

Singer, M.S. and D.E. Gottschling. 1994. TLC1: Template RNA component of Saccharomyces cerevisiae telomerase. Science 266: 404-409.

Sussel, L. and D. Shore. 1991. Separation of transcriptional activation and silencing functions of the RAP1-encoded repressor/activator protein 1: Isolation of viable mutants affecting both silencing and telomere length. Proc. Natl. Acad. Sci. 88: 7749-7753.

Thomas, B.J. and R. Rothstein. 1989. Elevated recombination rates in transcriptionally active DNA. Cell 56: 619-630.

Tornow, J., X. Zeng, W. Gao, and G.M. Santangelo. 1993. GCR1, a transcriptional activator in Saccharomyces cerevisiae, complexes with RAP1 and can function without its DNA binding domain. EMBO J. 12: 2431-2437.

Virta-Pearlman, V., D.K. Morris, and V. Lundblad. 1996. Est1 has the properties of a single-stranded telomere end-binding protein. Genes \& Dev. 10: 3094-3104.

Wiley, E.A. and V.A. Zakian. 1995. Extra telomeres, but not internal tracts of telomeric DNA, reduce transcriptional repression at Saccharomyces telomeres. Genetics 139: 67-79.

Wright, J.H., D.E. Gottschling, and V.A. Zakian. 1992. Saccharomyces telomeres assume a non-nucleosomal chromatin structure. Genes \& Dev. 6: 197-210.

Zakian, V.A. 1995a. Saccharomyces telomeres: Function, structure, and replication. In Telomeres (ed. E.H. Blackburn and C.W. Greider), pp. 107-137. Cold Spring Harbor Laboratory Press, Cold Spring Harobr, NY.

- 1995b. Telomeres: Beginning to understand the end. $S_{c i-}$ ence 270: 1601-1607. 


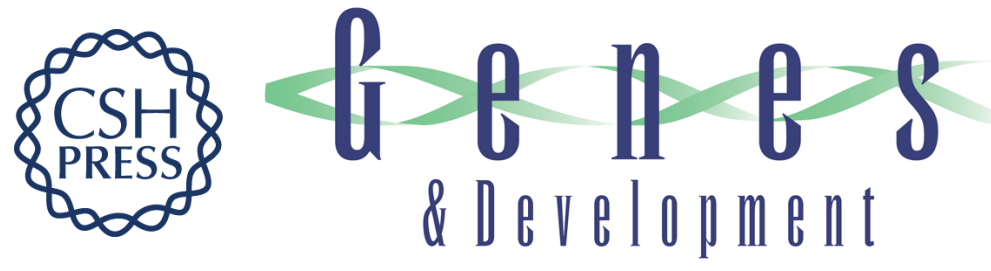

\section{A novel Rap1p-interacting factor, Rif2p, cooperates with Rif1p to regulate telomere length in Saccharomyces cerevisiae.}

D Wotton and D Shore

Genes Dev. 1997, 11:

Access the most recent version at doi:10.1101/gad.11.6.748

References This article cites 54 articles, 34 of which can be accessed free at:

http://genesdev.cshlp.org/content/11/6/748.full.html\#ref-list-1

License

Email Alerting

Service

Receive free email alerts when new articles cite this article - sign up in the box at the top right corner of the article or click here.

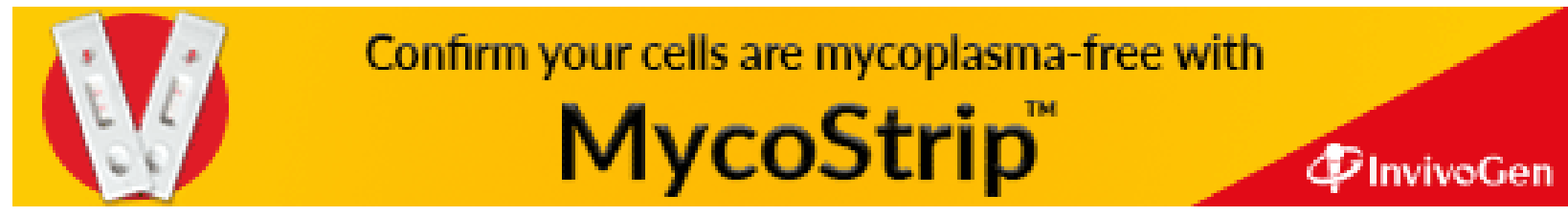

